\title{
PENERAPAN E-COMMERCE UNTUK PENJUALAN ROKOK ELEKTRIK (VAPE) MENGGUNAKAN CONTENT MANAGEMENT SYSTEM WORDPRESS PADA TOKO VAPE GRANDE
}

\author{
Estri Wulandari ${ }^{1)}$, Grace Gata ${ }^{2)}$ \\ ${ }^{1}$ Sistem Informasi, Fakultas Teknologi Informasi, Universitas Budi Luhur \\ ${ }^{1,2} \mathrm{JI}$. Raya Ciledug, Petukangan Utara, Kebayoran Lama, Jakarta Selatan 12260 \\ E-mail : estriwulandari13@gmail.com ${ }^{1)}$,grace.gata@budiluhur.ac.id ${ }^{2)}$
}

\begin{abstract}
Abstrak
Kegiatan jual-beli online atau E-Commerce menjadi salah satu transaksi yang sedang ramai digunakan, karena transaksi jual beli online sangat mempermudah transaksi. Sebagai contoh, transaksi yang ada pada toko Vape Grande, toko yang menjual liquid vape dan juga berbagai macam vaping stuff. Vape merupakan rokok elektrik yang pembakarannya berasal dari pemanasan baterai yang ada di dalam vape, dan sebagai perasa vape diisi oleh liquid yang memiliki varian rasa tertentu. Pembuatan laporan hasil penjualan toko Vape Grande menggunakan pembukuan yang kemudian dipindahkan kedalam Microsoft excel yang menyebabkan laporan tidak akurat. Peneliti menggunakan tools Unified Modelling Language (UML) yang didalamnya terdapat activity diagram, usecase diagram, class diagram, dan sequence diagram. Peneliti telah membuat penjualan dengan penerapan E-Commerce menggunakan Content Management Sytsem (CMS) Wordpress untuk mempermudah penjualan pada toko Vape Grande yang memiliki konsep E-Commerce agar toko dapat memiliki cakupan penjualan yang lebih luas dan lebih berkembang, yang juga dapat memudahkan akses informasi kepada pembeli atau pelanggan. Dengan adanya website E-commerce ini pelanggan lebih mudah mengetahui update produk terbaru dan infromasi terbaru yang ada pada toko vape grande.
\end{abstract}

Kata kunci: E-Commerce, Rokok Elektrik, Content Management System

\section{PENDAHULUAN}

Pengertian dari E-commerce adalah merupakan website yang dipergunakan untuk transaksi penjualan, ada juga yang memiliki pengertian lain yaitu electronical data interchange. Salah satu pengertian yang dapat memberikan presentasi pengertian E-commerce, yaitu adalah perangkat dari teknologi yang bersifat dinamis, yang didalamnya berisi aplikasi dan juga proses bisnis yang dapat membantu menghubungkan perusahaan, pelanggan dan juga suatu komunitas atau kelompok melalui transaksi elektronik, yang juga melakukan transaksi elektronik barang, jasa, dan informasi. [1].

Vape Grande adalah sebuah toko rokok elektrik yang biasa dikenal dengan sebutan vape, mengapa disebut rokok elektrik karena pembakaran rokoknya tersebut tidak menggunakan api melainkan menggunakan panas yang dihasilkan oleh aliran listrik yang berasal dari baterai yang berada didalam rokok elektrik. Pada toko Vape Grande menjual peralatan aksesoris yang berhubungan dengan rokok elektrik, seperti kapas, kawat, baterai vape serta menjual liquid atau cairan untuk perasa pada rokok elektrik dan juga mod. Kisaran harga liquid pada toko Vape Grande terbilang terjangkau dan tidak berbeda jauh dengan toko lain. Media promosi atau pemasaran pada toko ini yaitu melalui media sosial instagram yang hanya melakukan promosi saja atau hanya di jadikan katalog untuk pembeli agar dapat melihat dan memilih sebelum membeli. Pembeli tidak dapat melakukan pemesanan melalui media sosial instagram. Sehingga pembeli hanya dapat datang ke toko Vape Grande untuk melakukan pembelian, namun bagi pembeli yang sudah kenal atau yang sudah langganan biasanya akan menghubungi penjual via telepon lalu melakukan pemesanan, kemudian penjual akan mengirimkan pesanan kepada pembeli. Penjual juga memiliki grup dan forum antar sesama penjual maupun pengguna rokok elektrik, grup dan forum tersebut dipergunakan sebagai media informasi untuk kegiatan yang akan dilakukan sesama penjual rokok elektrik. Dengan begitu transaksi jual beli toko Vape Grande pada saat ini hanya dapat dilakukan via telepon dan juga datang langsung ke toko. Pembuatan laporan keuangan barang masih belum otomatis terbarui dan tersimpan karena penjual memindahkan data yang tertulis di kertas ke Microsoft excel, sehingga data tidak otomatis tersimpan setelah terjadi transaksi. Sehingga bisa dikatakan pengeluaran dan pemasukan menjadi kurang terkontrol. Dengan adanya peran Ecommerce diharapkan dapat membantu mempermudah transaksi maupun manajemen yang berada pada toko Vape Grande serta pula meningkatkan promosi toko agar pemasaran menjadi lebih luas. Maka dari itu peneliti merancang dan mengembangkan website berbasis E-commerce 
sebagai salah satu solusi atas permasalahan pada toko Vape Grande.

Adapun tujuan dan manfaat dari penulisan ini sebagai berikut :

1) Membuatkan website sehingga pembeli dapat melihat dan memilih produk dan juga langsung membeli di website tersebut tanpa harus ke toko.

2) Dibuatkan website penjualan untuk memperluas pemasaran dan menjangkau pembeli dari luar kota.

3) Menyediakan keranjang pembelian yang dapat secara otomatis akan menyimpan data pembelian barang sehingga lebih menghasilkan laporan yang tepat dan akurat.

Adapun manfaat dari penulisan diharapkan dapat memberikan masukan dan pertimbangan kepada manajemen Toko Vape Grande dalam teknik pemasaran dan penjualan dengan penerapan $e$ commerce.

\subsection{Content Management System (CMS)}

CMS merupakan singkatan dari Content Management System. CMS adalah sebuah aplikasi yang berbasis web yang biasa digunakan sebagai aplikasi untuk mengatur konten website. Hampir pada semua website memiliki CMS yang mengatur konten, kecuali website statis. Sebuah aplikasi CMS lebih sering memiliki kemampuan untuk memperbarui artikel, mengubah halaman website, menata menu dan tampilan pada website [2].

\subsection{Wordpress}

Wordpress merupakan suatu perangkat lunak CMS pembuatan website akan terus berkembang dari waktu ke waktu, akan selalu terupdate. Pada saat ini wordpress telah memasuki ke versi yang terbaru dimana akan semakin tepat dan sesuai dan juga banyak fitur-fitur baru [3].

\subsection{Penelitian Sebelumnya}

Galih Budhi Setiyo melakukan penelitian yang berjudul "Analisa Sistem E-Commerce Pada Perusahaan Jual Beli Online Lazada Indonesia” . Dari hasil Penelitian tersebut menjabarkan Lazada Indonesia merupakan toko belanja online yang sering digunakan di Indonesia dan juga dalam hal layanan terhadap pelanggan dapat dikatakan sangat ekstra. Lazada Indonesia mempunyai kekuatan dan kekurangan, kekuatan yang dimiliki adalah ketika membeli melalui website Lazada Indonesia maka pelanggan mendapatkan promo dan diskon tertentu, dengan adanya konsep atau tanpa konsep promo tertentu. Lalu kekurangan dari belanja pada website Lazada yaitu memiliki resiko bagi pelanggan yang masuk kedalam situs Lazada merasa tidak yakin pada kepada toko E-commerce yang ada, karena merasa nomor telepon yang ada tidak valid atau bohong. [4]

\section{METODE PENELITIAN}

Untuk melakukan penelitian ini peneliti menggunakan metode penelitian sebagai berikut :

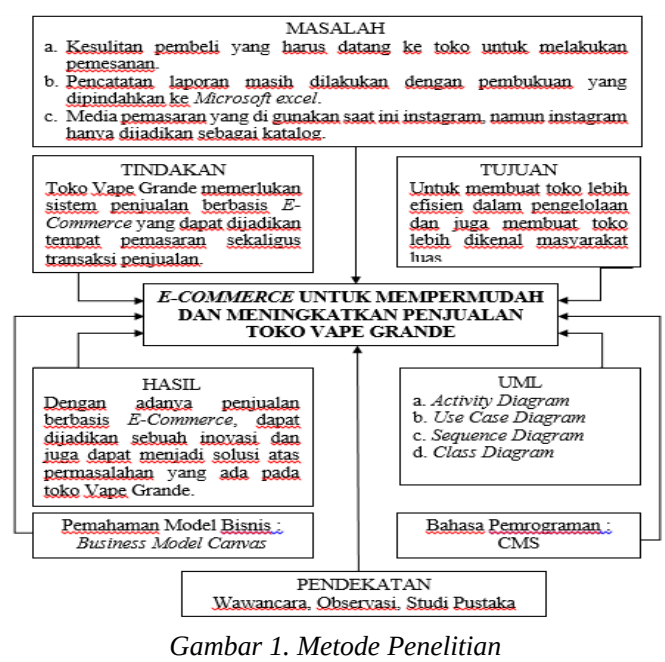

Berikut gambar 1. Metode Penelitian merupakan penjelasan mengenai:

\subsection{Masalah}

a. Kesulitan pembeli yang harus datang ke toko untuk melakukan pemesanan.

b. Pencatatan laporan masih dilakukan dengan pembukuan yang dipindahkan ke Microsoft excel.

c. Media pemasaran yang di gunakan saat ini instagram, namun instagram hanya dijadikan sebagai katalog.

\subsection{Tindakan}

Toko Vape Grande memerlukan system penjualan berbasis E-Commerce yang dapat dijadikan tempat pemasaran sekaligus transaksi penjualan.

\subsection{Tujuan}

Untuk membuat toko lebih efisien dalam pengelolaan dan juga membuat toko lebih dikenal masyarakat luas..

\subsection{Hasil}

Dengan adanya penjualan berbasis $E$ Commerce, dapat dijadikan sebuah inovasi dan juga dapat menjadi solusi atas permasalahan yang ada pada toko Vape Grande. 


\subsection{Perancangan}

Dalam tahap perancangan sistem menggunakan tools unified modeling language (UML) yang terdiri dari activity diagram, usecase diagram, class diagram, dan sequence diagram.

\subsection{Pemrograman}

Dalam penelitian peneliti menggunakan pemrograman CMS (content management system) menggunakan wordpress dengan plugin woocommerce untuk membuat program.

\subsection{Pemahaman Model Bisnis}

Pada Peneltian peneliti menggunakan business model canvas sebagai gambaran yang dapat menjelaskan atau mendeskripsikan pengelolaan toko Vape Grande.

\subsection{Pendekatan}

Pendekatan yang digunakan oleh peneliti dalam melakukan penelitian yaitu dengan cara wawancara, observasi, dan studi pustaka.

\section{HASIL DAN PEMBAHASAN}

\subsection{Business Model Canvas}

Peneliti menggunakan Business Model Canvas sebagai penjelasan dan juga gambaran aktivitas penjualan yang terjadi pada toko Vape Grande, dibawah ini merupakan Business Model Canvas yang telah peneliti buat.

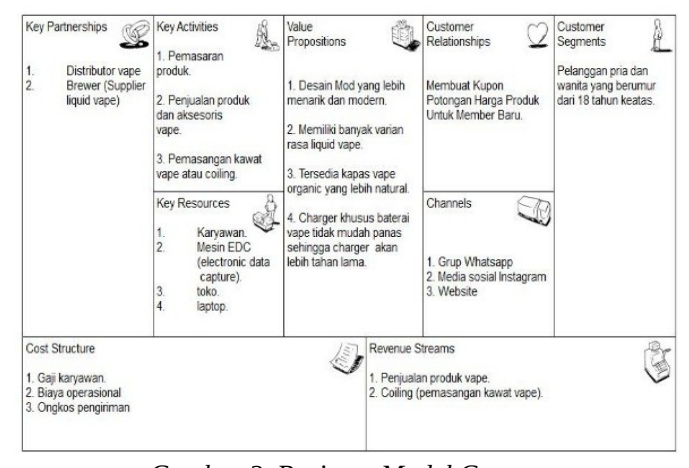

Gambar 2. Business Model Canvas

Berikut penjelasan mengenai gambar 2 . Business Model Canvas :

\section{a. Customer Segements}

Blok ini menjelaskan target atau sasaran pelanggan pada toko Vape Grande, sasaran pelangan yaitu pria dan wanita yang sudah berumur lebih dari 18 tahun.

\section{b. Customer Relatioship}

Pada blok ini menjelaskan bagaimana perusahaan membangun hubungan dengan pelanggan, yaitu dengan cara memberikan diskon atau promo sebagai bentuk menarik perhartian target pelanggan.

\section{c. Value Propositions}

Blok ini menjelaskan mengenai penawaran produk yang mempunyai keunggulan atau nilai lebih yang dimiliki oleh toko vape grande, keunggulan yang dimiliki yaitu desain mod lebih menarik dan modern, memiliki banyak varian rasa liquid vape, tersedia kapas vape organic, charger khusus baterai vape yang tidak mudah panas saat di charge.

\section{d. Key Activities}

Blok ini menjelaskan aktivitas kunci atau halhal penting yang dilakukan perusahaan agar model bisnis dapat berjalan dengan baik. Yang toko vape grande lakukan yaitu melakukan pemasaran atau promosi produk, melakukan penjualan produk dan aksesoris vape, dan juga melakukan coiling atau pemasangan kawat vape.

\section{e. Key Partnerships}

Pada blok ini menjelaskan hubungan antara pihak kedua atau partner utama perusahaan agar bisnis model bisnis dapat berjalan dengan baik, vape grande memiliki distributor yang menjadi partner utama sebagai pemasok liquid maupun aksesoris vape lain, dan juga ada brewer sebagai penyuplai liquid vape yang khusus hanya memproduksi liquid vape.

\section{f. Key Resources}

Blok ini menjelaskan tentang aset penting yang diperlukan agar model bisnis dapat berfungsi. Aset yang dimiliki toko vape grande yaitu mesin $E D C$ (electronic data capture), laptop, tenaga kerja/karyawan, toko.

\section{g. Channels}

Blok ini menjelaskan bagaimana perusahaan menjalin komunikasi dengan customer segments dan menjangkau mereka. Pada toko vape grande sebagai media komunikasi dengan pelanggan yaitu melalui grup whatsapp, media sosial instagram, dan website.

\section{h. Cost Structure}

Blok ini menjelaskan semua biaya yang dikeluarkan untuk mengoperasikan model bisnis. Biaya yang dikeluarkan oleh toko vape grande yaitu untuk gaji karyawan, biaya operasional toko, dan juga ongkos kirim baranng dari distributor menuju toko maupun pengiriman dari toko cabang satu ke cabang yang lain.

\section{i. Revenue Streams}

Pada Blok ini menjelaskan pendapatan yang dihasilkan perusahaan dari segmen pelanggan, inti dari blok ini menggambarkan bagaimana perusahaan menghasilkan uang. Untuk vape grande penghasilan berdasarkan hasil penjualan produk vape yaitu liquid maupun aksesoris lain, dan juga penghasilan berasal dari coiling atau pemasangan kawat vape. 


\subsection{Activity Diagram}

Activity Diagram adalah gambaran dari tiaptiap aktifitas yang terdapat pada sistem. Pada aktifitas sistem yang mewakili sebuah activity diagram [5] .

a. Proses Pendaftaran

Pelanggan membuka website kemudian pelanggan dapat memilih menu my account, didalam menu my account terdapat form login dan form register, untuk mendaftar pelanggan perlu mengisi form register kemudian klik tombol register. Lalu sistem akan memeriksa email atau username sudah pernah di gunakan atau belum, bila sudah maka pengunjung perlu mengisi form register dengan email atau username lain. Bila belum pernah digunakan maka sistem akan menyimpan data pelanggan, kemudian sistem akan mengirimkan notifikasi kepada pelanggan bahwa akun telah dibuat. Seperti yang dapat dilihat pada gambar 3 . Activity Diagram Proses Pendaftaran .

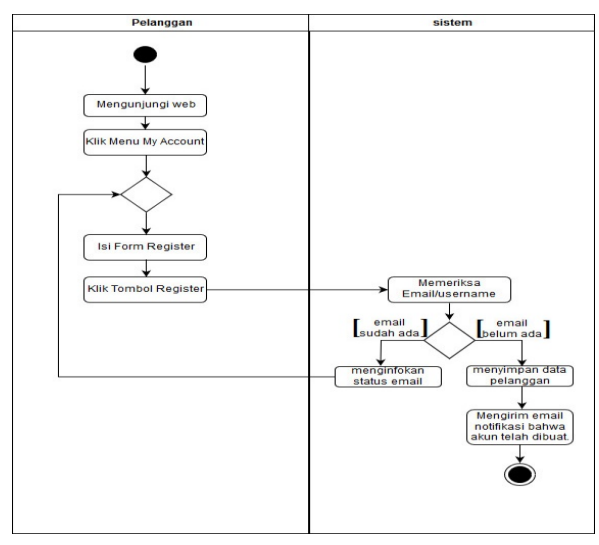

Gambar 3. Activity Diagram Proses Pendaftaran

Pada Gambar 3. Activity Diagram Proses Pendaftaran berisi tentang penjelasan mengenai tata cara pendaftaran pelanggan.

\section{b. Proses Login}

Untuk login pelanggan masuk kedalam website vape grande kemudian pelanggan pilih menu my account, dalam menu my account terdapat dua form yaitu form login dan registrasi, untuk login isi form login dengan memasukkan username dan password yang telah terdaftar pada website kemudian klik tombol login. Setelah itu sistem akan memeriksa apakah username dan password sudah benar atau belum. Bila password atau username belum tepat maka pelanggan akan mengisi form login kembali. Bila benar maka sistem akan menyimpan data pelanggan. Seperti yang dapat dilihat pada gambar 4 . Activity Diagram Proses Login .

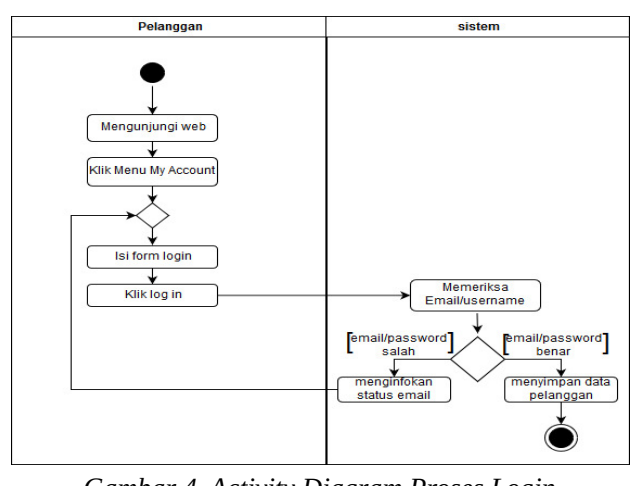

Gambar 4. Activity Diagram Proses Login

Pada gambar 4. Activity Diagram Proses Login berisi tentang proses login yang dilakukan oleh pelanggan.

\section{c. Proses Pemesanan}

Pelanggan dapat melakukan login pada website vape grande, kemudian pelanggan pilih menu shop setelah itu pelanggan pilih kategori dan jenis barang lalu sistem akan menampilkan gambar produk. Setelah sudah menentukan pilihan barang, pelanggan klik tombol add to chart, jika masih ingin berbelanja produk yang lain pelanggan dapat kembali klik tombol shop dan memilih kategori produk. Jika sudah selesai belanja pelanggan dapat melakukan proses checkout dengan menekan tombol proceed to checkout setelah itu pelanggan mengisi billing details, di dalam billing details pelanggan dapat memilih ekpedisi yang di inginkan, lalu sistem akan menampilkan total yang harus dibayarkan oleh pelanggan. Kemudian pelanggan dapat mengklik place order untuk menyelesaikan proses pemesanan, lalu pelanggan akan mendapatkan pemberitahuan melalui email bahwa pesanan telah diterima. Setelah itu sistem akan menyimpan data pesanan pelanggan.

Seperti yang dapat dilihat pada gambar 5 . Activity Diagram Pemesanan .

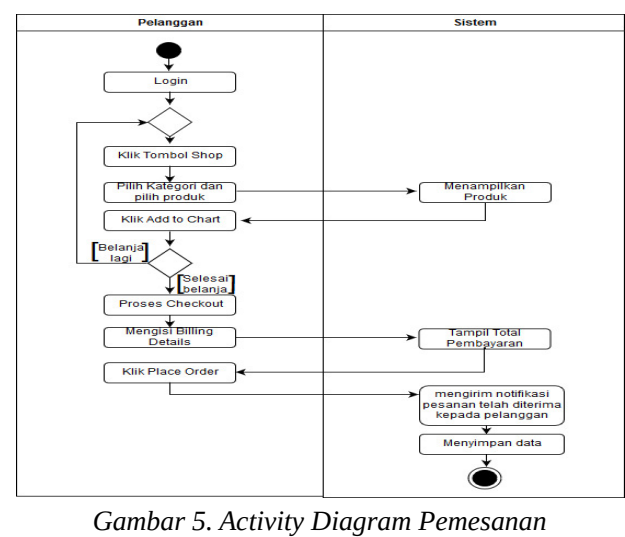

Pada gambar 5. Activity Diagram Pemesanan menjelaskan tentang proses pemesanan pada website Vape Grande. 
d. Proses Pembayaran

Dalam proses ini pelanggan terlebih dahulu melakukan pembayaran melalui bank, setelah itu pelanggan dapat membuka website vape grande kemudian pilih menu confirm payment, lalu sistem akan menampilkan form confirm payment yang perlu di isi lengkap oleh pelanggan, kemudian pelanggan upload bukti pembayaran atau transaksi, setelah itu klik submit. Jika sudah maka sistem akan menyimpan data pembayaran. Seperti yang dapat dilihat pada gambar 6. Activity Diagram Pembayaran .

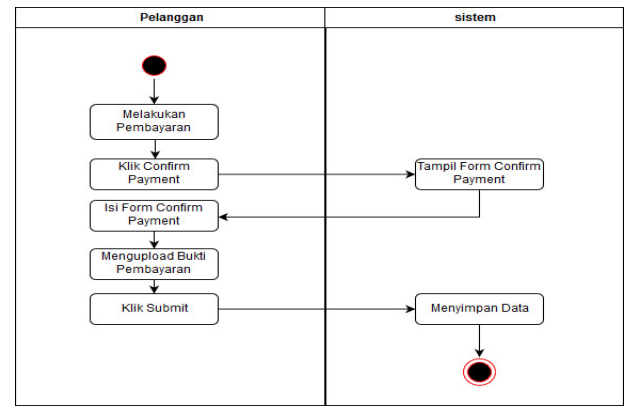

Gambar 6. Activity Diagram Pembayaran

Pada gambar 6. Activity Diagram Pembayaran menggambarkan tentang proses pembayaran yang dilakukan oleh pelanggan.

\section{e. Proses Laporan}

Dalam proses Laporan admin terlebih dahulu login, kemudian admin memilih menu laporan. Setelah itu pilih laporan penjualan, laporan potongan harga, laporan barang terlaris, laporan pengiriman dan laporan rekapitulasi yang akan diserahkan kepada pemilik toko. Seperti yang dapat dilihat pada gambar 7. Activity Diagram Laporan .

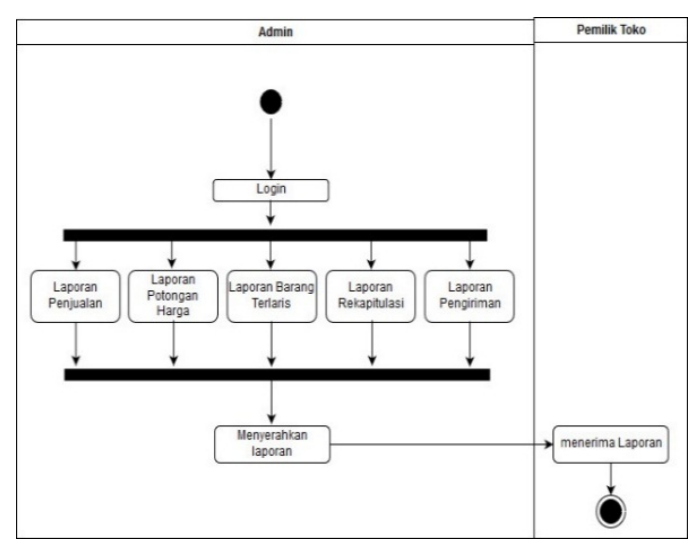

Gambar 7. Activity Diagram Laporan

Pada gambar 7. Activity Diagram Laporan berisi tentang laporan yang dimiliki toko Vape Grande.

\subsection{Use Case Diagram}

Use Case Diagram adalah gambaran aktifitas yang dapat dilakukan oleh actor atau sebagai pengguna yang ada pada use case diagram. Use Case Diagram juga memiliki tujuan yaitu menjelaskan konsep hubungan antara sistem dengan dunia luar [6]. Berikut adalah Use Case Diagram yang dibuat oleh peneliti :

a. Use case diagram master

Berikut merupakan Use Case Diagram master yang telah dibuat oleh peneliti :

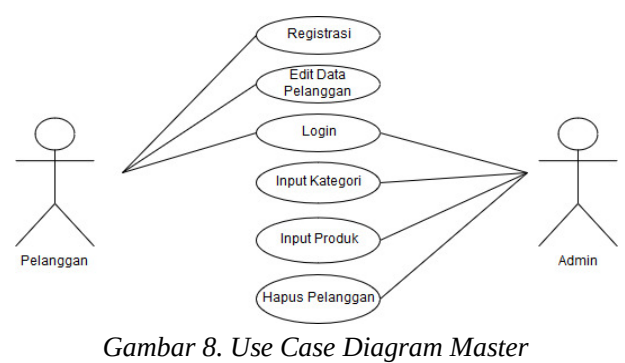

Pada gambar 8. Use Case Diagram master terdapat dua actor yaitu pelanggan dan admin, pada use case tersebut admin dapat melakukan registrasi, edit data pelanggan, dan juga login. Kemudian actor admin dapat melakukan login, input kategori, input produk, dan juga hapus pelanggan.

b. Use Case Diagram Transaksi

Berikut ini merupakan Use Case Diagram Transaksi :
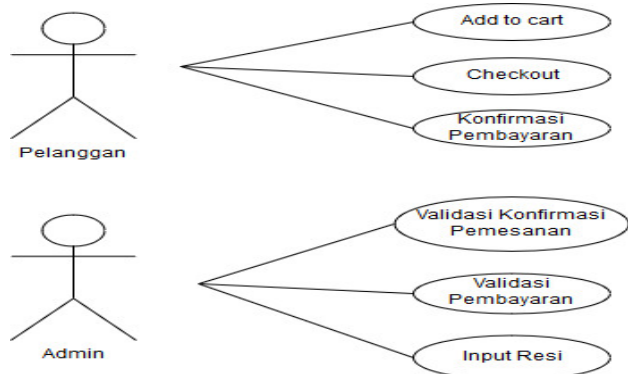

Gambar 9. Use Case Diagram Transaksi

Pada gambar 9. Use Case Diagram Transaksi berisi dua actor yaitu pelanggan dan admin, pada actor pelanggan dapat melakukan add to cart, checkout, dan konfirmasi pembayaran. Lalu pada actor admin dapat melakukan validasi konfirmasi pemesanan, validasi pemesanan, input resi.

c. Use Case Diagram Laporan

Berikut ini adalah Use case Diagram Laporan yang telah dibuat oleh peneliti : 


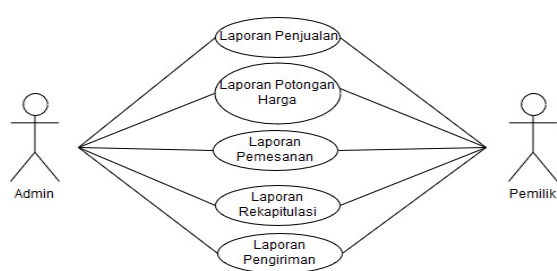

Gambar 10. Use Case Diagram Laporan

Pada gambar 10. Use Case Diagram Laporan terdapat dua actor yaitu admin dan pemilik toko, kedua actor sama-sama dapat mengakses ataupun mencetak laporan yang ada seperti laporan penjualan, laporan potongan harga, laporan pemesanan, laporan rekapitulasi, dan juga laporan pengiriman.

\subsection{Struktur Tampilan (Menu)}

a. Struktur Tampilan Menu Front End

Berikut ini merupakan struktur tampilan menu pelanggan yang ada pada toko Vape Grande :

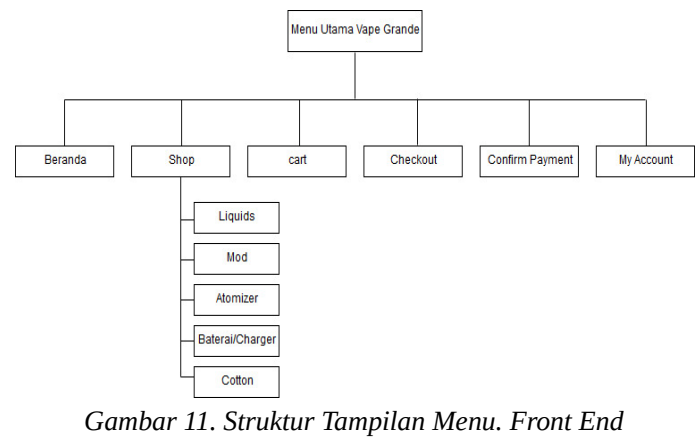

Pada gambar 11. Struktur tampilan menu front end menggambar tampilan menu pelanggan, seperti yang dapat dilihat pada gambar terdapat menu beranda, shop, cart, checkout, confirm payment, my account. Didalam menu shop terdapat submenu yaitu liquids, mod, atomizer, baterai/charge, cotton.

\section{b. Struktur Tampilan Menu Back End}

Pada gambar 12. Struktur tampilan menu back end merupakan struktur tampilan menu admin yang ada pada toko Vape Grande :

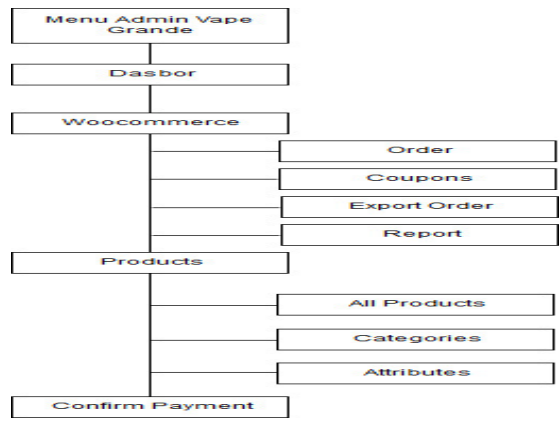

Gambar 12. Struktur Tampilan Menu Back End
Berdasarkan gambar 12. Struktur tampilan menu back end menggambarkan tentang tampilan menu admin. Terdapat menu dasbor, woocommerce, products, confirm payment. Pada menu woocommerce terdapat submenu order, coupons, export order, report. Pada menu products terpadat submenu all products, categories, dan juga attributes.

\subsection{Tampilan Layar}

a. Tampilan Website E-commerce

Berikut ini merupakan tampilan dari website toko Vape Grande :

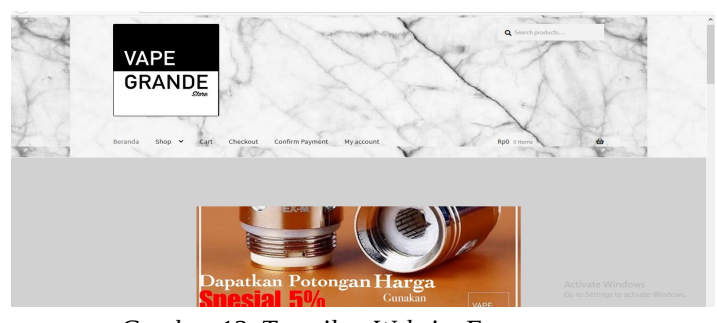

Gambar 13. Tampilan Website E-commerce

Pada Gambar 13. Tampilan website Ecommerce merupakan tampilan beranda dari website toko Vape Grande.

\section{b. Tampilan Order Complete}

Berikut ini adalah gambar 14. Tampilan order complete yang diterima oleh pelanggan dari hasil transaksi yang ada pada toko Vape Grande :

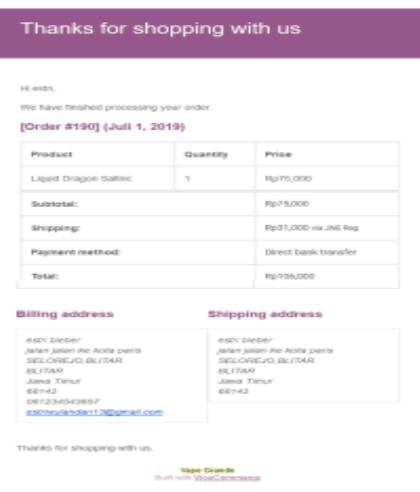

Gambar 14. Tampilan Order Complete

Pada Gambar 14. Tampilan order complete merupakan hasil transaksi yang diberikan kepada pelanggan dalam bentuk pemberitahuan bahwa transaksi telah selesai dilakukan.

c. Tampilan Laporan Potongan Harga

Berikut ini merupakan tampilan dari laoran potongan harga yang ada pada toko Vape Grande : 


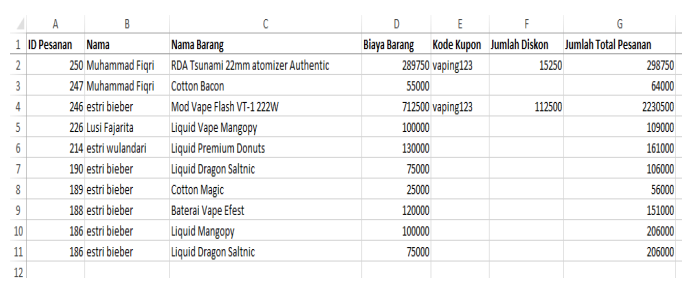

Gambar 15. Tampilan Laporan Potongan Harga

Pada Gambar 15. Tampilan laporan potongan harga berisi laporan potongan harga atau discount yang diberikan oleh pemilik toko untuk member baru yang mendaftar pada website Vape Grande.

d. Tampilan Laporan Pemesanan

Berikut ini merupakan dari laporan pemesanan yang ada pada website Vape Grande :

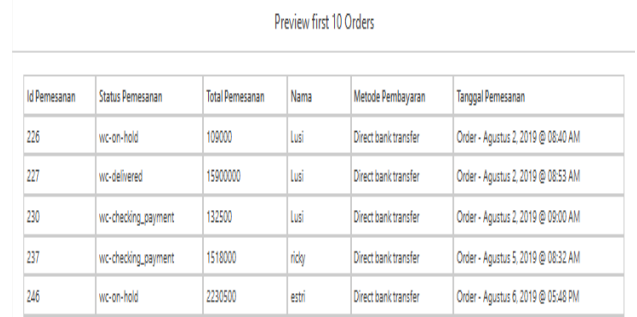

Gambar 16. Tampilan Laporan Pemesanan

Pada gambar 16. Tampilan Laporan Pemesanan merupakan hasil laporan dari setiap pemesanan yang dilakukan oleh pelanggan yang ada pada toko Vape Grande .

\section{KESIMPULAN}

Setelah peneliti melakukan penelitian dan peneliti membuat website E-commerce, maka dapat diberikan kesimpulan dan juga saran sebagai bentuk bagian tahap akhir atau disebut sebagai penutup dari laporan penelitian ini, yaitu dengan diterapkannya E-commerce pada toko vape grande sebagai media pemasaran dan juga media informasi kepada pelanggan yang diharapkan dapat mempermudah proses transaksi dalam penjualan. Website Ecommerce yang ada akan mempermudah pemilik toko atau pemilik usaha untuk mengetahui laporan penjualan, laporan pengiriman, laporan pemesanan, laporan potongan harga dan juga laporan rekapitulasi dalam setiap bulan. Ketiga sekaligus yang terakhir yaitu dengan adanya website E-commerce ini pelanggan lebih mudah mengetahui update produk terbaru dan informasi terbaru yang ada pada toko Vape Grande.

\section{DAFTAR PUSTAKA}

[1] Efendi Jonaedi, Kamus Istilah Hukum Populer. Jakarta:Prenadamedia Group, 2016.
[2] Abdulloh Rohi, Trik Mudah Membuat CMS Website dari Nol. Jakarta:PT Elex Media Komputindo, 2016.

[3] Rahman Su.. Mahir WordPress 4 Plus. Jakarta:PT Elex Media Komputindo, 2015.

[4] Budhi G. S., Analisis Sistem E-Commerce Pada Perusahan Jual-Beli Online LAZADA Indonesia. Jurnal Electronics, Informatics, and Vocational Education (ELINVO), 1(2), 78-82. Retrieved from https://journal.uny.ac.id/index.php/elinvo/article/dow nload/10880/8990, 2016.

[5] Azminuddin, Fundamental Perusahaan. Yogyakarta: Deepublish, 2019.

[6] Mulyani Sri, Metode Analisis dan Perancangan Sistem. Bandung:Abdi Sistematika, 2016. 